\title{
CULTURA OU CULTURAS? CONCEPCÕES DE CULTURA NA EDUCAÇÃO FÍSICA SOB A PERSPECTIVA DE CUCHE
}

\section{Luciana Maria Fernandes Silva}

Universidade Estadual Paulista Júlio de Mesquita Filho, Rio Claro, São Paulo, Brasil

\section{Luiz Gustavo Bonatto Rufino}

Universidade Estadual Paulista Júlio de Mesquita Filho, Rio Claro, São Paulo, Brasil

\section{Suraya Cristina Darido}

Universidade Estadual Paulista Júlio de Mesquita Filho, Rio Claro, São Paulo, Brasil

\section{Resumo}

Objetivando analisar e relacionar algumas obras da área da Educação Física, de acordo com as acepções de cultura especificadas por Cuche (2002), este trabalho pretendeu assinalar sob quais perspectivas esses referenciais estão ensejados e quais são as concepções de cultura corporal presentes em cada um. Embora muitas vezes as definições não sejam evidenciadas claramente, foi possível constatar tendências de aproximação a uma ou outra concepção de cultura, sendo ora compreendida na sua forma particularista, ora na sua forma universalista. Além disso, notou-se que essas definições não se opõem, mas se complementam, possibilitando à Educação Física compreender que ambos os sentidos contribuem para a ampliação do conhecimento sobre a cultura corporal.

Palavras-chave: Educação Física escolar. Cultura corporal. Epistemologia.

\section{Introdução}

partir da década de 1980 muitos autores brasileiros começaram
a defender uma concepção de Educação Física na escola influenciada pelas ciências humanas, na qual o conceito de cultura passou a protagonizar grande parte das discussões da área, sendo muitas vezes considerado como o centro dos questionamentos sobre a legitimidade e a especificidade desta que, anos mais tarde, tornou-se componente curricular obrigatório da educação básica.

De acordo com Bracht (1993), até a década de 1970 havia na área da Educação Física um predomínio das subáreas da medicina esportiva, da fisiologia e da cineantropometria, ou seja, a Educação Física sofria uma forte influência das ciências naturais. Porém, a partir de 
1980, verificou-se um crescimento do número de pesquisas nas áreas pedagógica e sociocultural, influenciadas pelas ciências sociais e humanas (BRACHT, 1993).

Betti (2009) corrobora essa visão ao constatar que a pesquisa em Educação Física escolar, a partir da década de 1980, foi marcada por uma grande produção de ensaios teóricos, estudos filosóficos, históricos e pedagógicos que transformou a visão anteriormente considerada pelos pesquisadores.

Esse aporte sociocultural proporcionou novos paradigmas para a Educação Física, abarcando conceitos advindos de outras áreas, bem como influências de diferentes escolas filosóficas, sociológicas e até mesmo políticas, modificando o que até então era considerado o papel da Educação Física na escola - o "saber fazer" esportivista - e, por isso, passível de ser transmitido nas aulas.

Para Forquin (1993), toda educação do tipo escolar realiza uma seleção no interior da cultura e uma re-elaboração dos conteúdos dessa cultura destinados a serem transmitidos às novas gerações. Assim, a educação não transmite a cultura e, sim, algo da cultura, que pode provir de fontes diversas e de diferentes épocas (FORQUIN, 1993).

Esse autor afirma, ainda, que o conteúdo que se transmite na educação é sempre alguma coisa que nos precede, nos ultrapassa e nos institui enquanto sujeitos humanos, dando-se a isso o nome de cultura. E que cultura é o conteúdo substancial da educação, sendo a sua justificação, pois para o autor a educação não é nada fora da cultura e sem ela (FORQUIN, 1993).

Na Educação Física, essa concepção de cultura está presente, por exemplo, em Daolio (2007), quando frisa que essa disciplina precisa considerar o ser humano em suas manifestações culturais relacionadas ao corpo e aos seus movimentos historicamente definidos como jogo, esporte, dança, luta e ginástica.

A concepção de cultura corporal (ou cultura corporal de movimento, entre outras) proporcionou uma identidade à Educação Física, transformando-se nos conteúdos específicos que devem ser transmitidos na e pela escola.

No entanto, essa concepção traz também divergências que extrapolam o âmbito da Educação Física. O conceito de cultura, desde sua origem, passou por diferentes definições e escolas de pensamento que alteraram os sentidos e desdobramentos desse termo, empregado de diversas maneiras e caracterizado em inúmeras situações. 
É importante ampliar as compreensões sobre o conceito de cultura difundido na área da Educação Física escolar, tendo em vista que o termo pode tomar diferentes caracterizações e abranger diversas acepções, umas mais universalistas, outras mais particularistas, dependendo do contexto no qual está inserido sem, com isso, excluir a outra concepção, permitindo que elas possam coexistir, sendo constantemente re-significadas.

\section{Objetivo}

O objetivo do estudo foi analisar as concepções de cultura de alguns autores clássicos e documentos da área da Educação Física, buscando compreender qual o sentido do conceito de cultura apresentado por esses autores a partir das concepções de cultura particularista e universalista proposta por Cuche (2002).

\section{Resultados e discussão}

A diferenciação entre as concepções de cultura universalista e particularista apresentada por Cuche (2002) não aparece explicitamente proposta nas obras da área da Educação Física. Entretanto, é possível constatar que alguns referenciais são baseados mais em uma concepção do que em outra. Por meio da diferenciação proposta por esse autor, é possível caracterizar algumas dessas obras como pertencentes a uma determinada concepção, embora o limite sobre cada uma delas seja às vezes pouco demarcado.

Assim, serão analisadas a seguir, primeiramente, as concepções sobre o conceito de cultura advindas de Cuche (2002) e, a partir disso, será caracterizada a cultura corporal para alguns autores e propostas da área da Educação Física. Finalmente, serão diferenciadas as concepções mais particularistas das mais universalistas presentes nas obras analisadas, relacionando, assim, essas diferenciações com o que é proposto pelas obras para a Educação Física na escola.

\section{Cuche e as concepções de cultura}

Não será realizada aqui uma extensa revisão da gênese do conceito de cultura, pois isso fugiria do escopo ao qual este trabalho se propõe. No entanto, é necessário compreender, mesmo que em linhas gerais, 
as origens da utilização do conceito de cultura, sobretudo no que diz respeito aos desdobramentos que essas definições provocaram à concepção de cultura utilizada atualmente na área da Educação Física.

Para Cuche (2002), o termo "cultura" é uma palavra oriunda do latim e significa "cuidado dispensado ao campo ou ao gado", utilizada no vocabulário francês. $\mathrm{O}$ autor realiza uma genealogia do conceito de cultura ao longo dos anos e suas transformações semânticas, caracterizando as diferenças em algumas sociedades distintas, sobretudo as diferenças de utilização do termo entre os países da França e da Alemanha.

É somente a partir do século XVI que há um processo de mudança do significado da palavra "cultura" que, do sentido literal de "coisa cultivada", passa a tomar forma em seu sentido figurado de cultura como uma faculdade, ou "trabalho para desenvolver o espírito", como se popularizou no século XVIII (CUCHE, 2002). É esse sentido figurado que foi se desenvolvendo ao longo dos séculos e que repercutiu nas definições contemporâneas sobre o termo cultura.

O iluminismo foi determinante para o emprego do conceito de cultura nesse sentido figurado. A palavra foi associada aos ideais de progresso, de evolução, de educação, de razão que estavam no centro do pensamento da época (CUCHE, 2002). Para esse autor, "a ideia de cultura participa do otimismo do momento, baseado na confiança no futuro perfeito do ser humano. O progresso nasce da instrução, isto é, da cultura, cada vez mais abrangente" (CUCHE, 2002, p. 21).

A Alemanha possui papel de destaque para a divulgação do termo "cultura", pois o adotou em função de querer opor-se ao pensamento francês da época. Enquanto o termo popularizava-se na Alemanha, a França optava pela utilização da terminologia "civilização", o que provocou diferenças entre as acepções de cultura para cada uma dessas sociedades (CUCHE, 2002).

Do debate ideológico e da oposição entre esses dois países, surgem duas concepções diferentes sobre o mesmo termo. Dessa forma, a concepção particularista de cultura foi promulgada pela Alemanha, visando enaltecer as conquistas artísticas e morais dessa sociedade, fortalecendo-se como patrimônio e como nação, como unidade específica. Já a França conduziu o conceito de cultura a uma concepção mais universalista, influenciada pela utilização do termo "civilização", fortalecendo uma dimensão coletiva da palavra, normalmente em um sentido vasto e impreciso (CUCHE, 2002). 
Na concepção universalista, cultura é a expressão da totalidade da vida social do homem, caracterizando-se sob o sentido de conjunto, sendo "adquirida". Para Tylor (apud CUCHE, 2002), todos os humanos são totalmente seres de cultura e as características de cada povo são dignas de valor, passíveis de contribuir com o progresso universal, pois, apesar de sua diversidade, algo mais amplo os une: a humanidade.

A concepção particularista, também denominada de relativista, privilegia "as culturas", separadas entre si e particulares, onde cada uma é única e original, e um costume somente pode ser explicado a partir da análise de seu contexto cultural - língua, crenças, costumes -, influenciando no comportamento dos indivíduos, no seu estilo próprio e único de ser "homem" (CUCHE, 2002, p. 46).

Assim, as diferenciações entre cultura universalista ou particularista originaram-se em países com interesses e objetivos específicos, muitas vezes estipulados literalmente para opor-se à concepção apresentada pelo outro, num embate que desmembrou em duas formas de acepção da palavra, compreendida em cada um desses sentidos de maneira muito particular, proporcionando diferentes compreensões no que se entende por cultura na sociedade contemporânea.

Segundo Cuche (2002), a dificuldade hoje está em saber se se utiliza o termo no singular, "a cultura", ou no plural, "as culturas", ou seja, se a concepção de cultura deve ser universalista ou particularista, respectivamente.

Dessa forma, a análise de alguns documentos clássicos da Educação Física, como os Parâmetros Curriculares Nacionais (BRASIL, 1998), Metodologia do Ensino da Educação Física do Coletivo de Autores (SOARES et al., 1992) e as concepções de Jocimar Daolio (DAOLIO, 2010; 2007; 2002; 1998), com o objetivo de investigar sobre qual concepção de cultura esses autores estão apoiados se faz pertinente, ao se referirem à cultura ou às culturas, e mais especificamente à cultura corporal, conceito muito difundido na área da Educação Física escolar.

\section{Educação Física e cultura corporal}

A seguir, serão apresentadas algumas definições sobre a perspectiva da cultura corporal apresentadas por alguns autores e propostas curriculares da área da Educação Física. Para Soares et al. (1992, p. 
50), a Educação Física escolar tem como um de seus conceitos fundamentais a reflexão sobre a cultura corporal. Segundo os autores, essa dinâmica curricular tem características bem diferenciadas das tendências anteriores, uma vez que eles a definem como uma "prática pedagógica que, no âmbito escolar, tematiza formas de atividades expressivas corporais como: jogo, esporte, dança, ginástica, formas estas que configuram uma área de conhecimento que podemos chamar de cultura corporal".

Refletir sobre a cultura corporal envolve considerar esse acervo de formas e representações corporais do mundo, de extrema importância - tanto histórica quanto social - assim, possibilita à Educação Física formular um recorte epistemológico próprio, tratando de diversos conteúdos que fazem parte da esfera da cultura corporal (SOARES et al., 1992).

Soares (1996) relata também que, historicamente, a Educação Física ocidental moderna tem ensinado o jogo, a ginástica, as lutas, a dança e os esportes, sendo considerados como "conteúdos clássicos que permaneceram através do tempo transformando inúmeros de seus aspectos, para se afirmar como elementos da cultura, como linguagem singular do homem no tempo" (SOARES, 1996, p. 11).

Betti (2009) também relaciona o conceito de cultura à Educação Física, denominado pelo autor de "Cultura Corporal de Movimento". Para ele, a Educação Física escolar conceitua-se como:

[...] uma disciplina que tem por finalidade propiciar aos alunos a apropriação crítica da Cultura Corporal de Movimento, visando formar o cidadão que possa usufruir, compartilhar, produzir e transformar as formas culturais do exercício da motricidade humana: jogo, esporte, ginásticas e práticas de aptidão física, dança e atividades rítmicas/expressivas, lutas/artes marciais, práticas alternativas. (BETTI, 2009, p. 64)

Cultura Corporal de movimento também é a denominação utilizada pelos Parâmetros Curriculares Nacionais (PCNs/BRASIL, 1998, p. 26), que entendem que a Educação Física, como componente curricular pode ser percebida como uma área que trata desse tipo de conhecimento e que tem como temas "o jogo, a ginástica, o esporte, as lutas, a dança, a capoeira e outras temáticas". 
Daólio (2007), contribuindo para o enriquecimento dessa compreensão, afirma que a Educação Física, a partir da revisão do conceito de corpo considerando a dimensão cultural simbólica defendida por Clifford Geertz, pode ampliar seus horizontes, abandonando a ideia de área que estuda o movimento humano, o corpo físico ou o esporte na sua dimensão técnica, para vir a ser uma área que considera o ser humano eminentemente cultural, contínuo construtor de sua cultura relacionada aos aspectos corporais. Assim, "a Educação Física pode, de fato, ser considerada a área que estuda e atua sobre a cultura corporal de movimento" (DAÓLIO, 2007, p. 9).

Ou seja, diversos autores e propostas curriculares propõem a cultura corporal - expressão utilizada neste trabalho por facilidade sintática - como o objeto de estudo próprio da Educação Física, representada por diversas manifestações corporais enraizadas na cultura. Entretanto, não se percebe claramente nessas propostas sobre qual concepção de cultura estão apoiadas, se universalista ou particularista, segundo Cuche (2002).

Levando em consideração que as duas acepções são igualmente importantes, tanto no que se refere ao seu entendimento como a sua consequente utilização pelos professores, este estudo se propõe a investigar alguns documentos de referência na área, como será constatado a seguir, no sentido de contribuir para seu desenvolvimento e disseminação, não tendo a pretensão de ser este um estudo acabado, mas, sim, de despertar outras reflexões.

\section{Educação Física: a concepção universalista de cultura}

Conforme constatado anteriormente, a concepção universalista, também denominada de etnocêntrica, pressupõe a diversidade inserida em uma igualdade: a humanidade. Cuche (2002) afirma que o outro não é nunca absolutamente outro e que há sempre algo de nós nos outros, porque a humanidade é uma só e a cultura está no centro das culturas, segundo a expressão que "o universal está no interior do particular".

No que se refere à cultura corporal, a obra Metodologia do Ensino da Educação Física do Coletivo de Autores (SOARES et al., 1992) afirma que a área 
[b]usca desenvolver uma reflexão pedagógica sobre o acervo de formas de representação do mundo que o homem tem produzido no decorrer da história, exteriorizadas pela expressão corporal: jogos, danças, lutas, exercícios ginásticos, esporte, malabarismo, contorcionismo, mímica e outros, que podem ser identificados como formas de representação simbólica de realidades vividas pelo homem, historicamente criadas e culturalmente desenvolvidas. (SOARES et al., 1992, p. 38)

Essa definição aproxima-se da perspectiva universalista proposta por Cuche (2002), uma vez que essas práticas corporais podem ser compreendidas como formas de representar o mundo, construídas pelo homem por meio de sua história e desenvolvidas pela cultura, comprovando a existência de uma igualdade em meio à diversidade humana. Para os autores, existe uma cultura corporal que é "resultado de conhecimentos socialmente produzidos e historicamente acumulados pela humanidade que necessitam ser retraçados e transmitidos para os alunos na escola" (SOARES et al., 1992, p. 39).

Percebe-se, ainda, uma tendência à concepção universalista de $\mathrm{Cu}$ che (2002) quando os autores se expressam com relação aos conteúdos específicos trabalhados pela Educação Física, sugerindo que sejam sistematizados em nível escolar, para o ensino fundamental e médio, utilizando-se de alguns exemplos desse universo, como o jogo, o esporte, futebol, atletismo, voleibol, basquetebol, capoeira, ginástica e dança (SOARES et al., 1992).

Os autores consideram também que, na perspectiva da reflexão da cultura corporal, "a expressão corporal é uma linguagem, um conhecimento universal, patrimônio da humanidade que igualmente precisa ser transmitido e assimilado pelos alunos na escola" (SOARES et al., 1992, p. 42).

Assim sendo, a cultura corporal, nessa obra, é considerada um conhecimento universal, de importância histórica e social, que é construído pelo homem e passível de ser transmitido pela escola, nas aulas de Educação Física. Entende-se que "a cultura" traz em si algo maior e mais amplo do que as especificidades existentes "nas culturas", que, no entanto, se complementam, ou, como afirma Forquin (1993), há uma reciprocidade entre essas acepções que não são fundamentalmente excludentes entre si e podem às vezes coexistir em um mesmo 
contexto, enfatizando que o que é importante, para a educação, é que cada uma dessas ideias fiquem claras.

Do mesmo modo, os Parâmetros Curriculares Nacionais (BRASIL, 1998) elaboram uma proposta curricular nacional para a Educação Física escolar, designando os objetivos gerais de ensino, compreendendo a cultura corporal de movimento como conceito fundamental da área. Para os autores:

O ser humano, desde suas origens, produziu cultura. Sua história é uma história de cultura na medida em que tudo o que faz é parte de um contexto em que se produzem e reproduzem conhecimentos. $\mathrm{O}$ conceito de cultura é aqui entendido, simultaneamente, como produto da sociedade e como processo dinâmico que vai constituindo e transformando a coletividade à qual os indivíduos pertencem, antecedendo-os e transcendendoos. (BRASIL, 1998, p. 27)

Portanto, o documento entende a Educação Física como a disciplina responsável por introduzir e integrar o aluno na esfera da cultura corporal de movimento, contribuindo para a formação de sua cidadania, permitindo que ele produza, reproduza e transforme essa cultura, instrumentalizando-o para usufruir dos jogos, dos esportes, das danças, das lutas e das ginásticas (BRASIL, 1998).

Nesse sentido, compreende-se a aproximação desse documento à concepção universalista de Cuche (2002). Ao mencionar que é preciso introduzir o aluno na esfera da cultura corporal de movimento, subtende-se que exista uma cultura ampla, de fundamental importância, e que por isso é necessário ser transmitida, ou seja, há algo maior que o aluno precisa apropriar-se criticamente, entendendo o termo no singular, "cultura".

No volume em que os PCNs (BRASIL, 1997) tratam especificamente o tema da pluralidade cultural, percebe-se uma maneira comum de pensar humanidade quando o documento descreve que essa temática diz respeito ao conhecimento e à valorização das características étnicas e culturais dos diferentes grupos sociais que convivem no território nacional. Afirma, ainda, que o Brasil representa uma esperança de superação de fronteiras e de construção da relação de confiança na humanidade e que, do ponto de vista de dignidade, de Direitos Universais, há uma só humanidade (BRASIL, 1997). 
Essas premissas remetem à concepção universalista apresentada por Cuche (2002) e corroboram com Forquin (1993), quando o autor preconiza que se deve conceder um espaço no vocabulário atual da educação à noção universalista e unitária de "cultura humana", isto é, à ideia de que o essencial daquilo que a educação transmite sempre, e por toda parte, transcende necessariamente as fronteiras entre os grupos humanos e os particularismos mentais e advém de uma memória comum e de um destino comum a toda a humanidade.

Contudo, ressalta-se a impossibilidade de determinar as obras analisadas com visões que somente se apoiam na concepção universalista de Cuche (2002), pois, concomitantemente, esses referenciais perpassam entre o universal e o particular quando, por exemplo, se preocupam que os conteúdos da Educação Física na escola estejam voltados para a realidade social do aluno e da comunidade local, considerando suas expectativas e interesses.

\section{Educação Física: a concepção particularista de cultura}

Para Daolio (2007), "cultura" é o principal conceito para a Educação Física, porque todas as manifestações corporais humanas são geradas na dinâmica cultural, desde os primórdios da evolução até hoje, expressando-se diversificadamente e com significados próprios no contexto de grupos específicos.

O autor salienta que a Educação Física trata do ser humano nas suas manifestações culturais relacionadas ao movimento humano em contextos específicos. Para o autor, o que define se uma ação corporal é digna de trato pedagógico pela Educação Física é a própria consideração e análise dessa expressão na dinâmica cultural específica do contexto onde se realiza (DAOLIO, 2007). Essa afirmação de relatividade das culturas será o principal conceito de Daolio abordado neste texto.

Para defender as especificidades de cada grupo social, o autor baseia-se em alguns referenciais da Antropologia Social, sobretudo alguns clássicos, como Marcel Mauss ${ }^{1}$, em que o autor analisa a concepção de "técnicas corporais", por exemplo, e Clifford Geertz

1-Mauss apud Daólio (2007) define técnicas corporais como sendo "as maneiras pelas quais os seres humanos, de forma tradicional e específica, utilizam seus corpos" (DAÓLIO, 2007, p. 4).

Pensar a Prática, Goiânia, v. 15, n. 4, p. 821-1113, out./dez. 2012 1022 
(1989), apoiando-se nas discussões sobre cultura, dimensão simbólica humana e crítica à concepção estratigráfica (que divide o ser humano em camadas, tendo o nível biológico como núcleo, superposto pelos estratos psicológico, social e cultural), entre outros conceitos desse autor.

Daolio (2007) analisa a concepção de cultura de Geertz, afirmando que, para esse autor, a cultura é a própria condição de vida de todos os seres humanos. É produto das ações humanas, mas é também processo contínuo pelo qual as pessoas dão sentido às suas ações. Ele afirma também que a cultura constitui-se em processo singular e privado, mas é também plural e público, admitindo que esse conceito pode ser compreendido como universal, uma vez que todos os seres humanos a produzem, mas é também local, uma vez que é a dinâmica específica de vida que significa o que o ser humano faz (DAOLIO, 2007).

Essa concepção da especificidade de cada cultura é mais presente na obra de Daolio, uma vez que o autor admite que "a cultura ocorre na mediação entre os indivíduos, manipulando padrões de significados que fazem sentido num contexto específico" (DAOLIO, 2007, p. 7).

A presença da particularidade e da compreensão de cada cultura, sem subjugar ou enaltecer uma em detrimento da outra, se faz marcante para esse autor, influenciando suas opiniões com relação à forma de ensinar a Educação Física na escola, que deve levar em consideração os contextos específicos de cada grupo social, valorizando as particularidades, compreendendo o homem como contínuo construtor de sua cultura (DAOLIO, 2002). O autor admite que:

A discussão cultural oriunda da Antropologia Social parece ter contribuído também para um aprofundamento e qualificação dos debates sobre a Educação Física escolar. Primeiramente porque o homem passou a ser considerado além de sua dimensão biológica. Sendo um indivíduo que se localiza num determinado contexto e num determinado momento histórico, qualquer intervenção pedagógica sobre ele deve levar em conta esses aspectos. (DAOLIO, 2002, p. 13)

Devido a essa concepção das particularidades de cada região, o autor se coloca contrário à elaboração e utilização de rígidos progra- 
mas e planejamentos na Educação Física (DAOLIO, 2002), exemplificando esta questão com uma ilustração:

Nas minhas aulas [...] costumo ilustrar essa questão dizendo que um professor formado em Educação Física em Campinas teria condições de trabalhar em qualquer região brasileira, desde que fosse capaz de fazer as leituras de significados dos conteúdos (jogo, ginástica, esporte, dança, luta) da região específica, a fim de fazer as mediações necessárias entre o conhecimento específico e o conhecimento elaborado. (DAOLIO, 2002, p. 19)

Daolio (2007) considera que o profissional de Educação Física precisa "saber ler, aceitar e compreender os significados originais do grupo alvo de seu trabalho, [...] considerando também os seus significados e aqueles atribuídos ao longo da tradição da cultura corporal de movimento" (DAOLIO, 2007, p. 55-56).

Enfatizando a questão da valorização dos contextos específicos, o autor afirma que "a análise cultural tem procurado compreender a imensa e rica tradição da área que, durante anos, a definiu como ela se apresenta hoje e, ao mesmo tempo, tem procurado entender suas várias manifestações como expressões de contextos específicos" (DAOLIO, 2007, p. 10).

Em outra obra, o autor reafirma que, se for assumido que o conhecimento popular corporal ocorre diferentemente em função do contexto, possuindo significados específicos, não é possível defender o desenvolvimento dos mesmos conteúdos de forma sequencial, centralizada e nacional (DAOLIO, 2010). E questiona: "como garantir, ao mesmo tempo, a unidade da Educação Física escolar e a consideração da diversidade necessária para a intervenção da área?" (DAOLIO, 2010, p. 12-13).

Essa compreensão dos contextos específicos torna-se presente até mesmo quando o autor analisa o universo e a manipulação de símbolos no processo de criação e transformação das modalidades esportivas (DAOLIO, 1998, p. 112):

Esse processo de criação e de transformação de uma modalidade esportiva dá-se por meio de uma manipulação de símbolos, característica que distingue o homem de outros animais. O ho- 
mem vai atribuindo significados a tudo o que faz, procurando dar sentido às suas ações. São esses significados que diferenciam os inúmeros grupos humanos espalhados pelo mundo e ao longo da história. Assim, uma mesma modalidade esportiva, mundialmente codificada com regras e técnicas definidas por uma confederação, é praticada com estilos diferentes, porque os significados a ela atribuídos pelos diversos grupos são diferentes.

Dessa forma, é possível delinear a obra de Daolio como se aproximando da concepção particularista ou relativista de cultura de acordo com Cuche (2002), que afirma que a ideia de relatividade das culturas é impressa a partir do reconhecimento de que todas são importantes, sendo impossível uma hierarquização a priori, possibilitando o surgimento de algumas indagações, entre elas: Como pensar a especificidade humana na diversidade dos povos e dos costumes? Privilegiar a diversidade ou a unidade?

As posições de Daolio se aproximam da concepção de cultura que Cuche (2002) denomina de relativista, porque, nessa perspectiva, toda a importância da cultura é dada à diversidade, em oposição à visão universalista, que privilegia a unidade. De acordo com Cuche (2002), não há entendimento entre os antropólogos sobre a utilização do conceito de cultura no singular (a cultura) ou no plural (as culturas), em uma acepção universalista ou particularista.

Relativismo cultural para Cuche (2002) é, antes de tudo, um princípio metodológico. A fim de escapar de qualquer forma de etnocentrismo no estudo de uma cultura particular, recomenda-se abordá-la sem a priori, sem aplicar suas próprias categorias para interpretá-la, sem compará-la prematuramente a outras culturas (CUCHE, 2002). Nessa perspectiva, cada cultura é dotada de um estilo particular que se exprime por meio da língua, das crenças, dos costumes e da arte, podendo ser expandida também para o corpo e o conceito de cultura corporal.

Todavia, a partir dessas análises, não é possível classificar a obra de Daolio como sendo inteiramente voltada à questão da relatividade cultural, uma vez que o próprio autor admitiu que, embora o relativismo seja um procedimento básico da prática de pesquisa antropológica, ele não pode ser "levado às últimas consequências, a um vale tudo 
onde a própria pesquisa deixaria de ter sentido" (DAOLIO, 2002, p. 29).

É possível, designar, por outro lado, certa tendência de caracterização da obra desse autor no enfoque mais particularista/relativista proposto por Cuche (2002), não necessariamente servindo para "rotular" ou "enquadrar" o autor ou sua obra apenas nessa concepção, mas compreendendo que algumas ideias apoiam-se mais nesse enfoque do que na tendência universalista.

\section{Considerações finais}

Visando responder à pergunta que norteou este trabalho - sobre qual o sentido do conceito de cultura apresentado por alguns autores da Educação Física a partir das concepções de cultura particularista e universalista preconizadas por Cuche (2002) -, buscou-se analisar as obras citadas para compreender sobre qual dessas perspectivas elas se apoiam, uma vez que a cultura corporal é conceito fundamental da área.

Entender o conceito de cultura corporal e outras denominações que a pressupõem foi exponencial para que se aportasse na compreensão daquilo que Cuche (2002) denomina de concepção universalista de cultura - a diversidade inserida em uma igualdade: a humanidade - e a concepção particularista de cultura - cada cultura é dotada de um estilo particular que se exprime por meio da língua, das crenças, dos costumes e das artes; e assim, relacioná-las.

Foi possível, portanto, perceber que, na Educação Física, o conceito de cultura se apresenta ora em uma acepção mais universalista, ora em uma acepção mais particularista. Isso se deve ao fato de a influência das abordagens socioculturais ter se dado por escolas diferentes, tendo direcionado os autores da área, que, a partir dessas concepções, propuseram formas de compreender o conceito de cultura corporal.

Esse "caminho do meio", por não ser nem apenas uma concepção e nem somente a outra, e, ao mesmo tempo, por convergir uma na outra, constitui-se na relação dos indivíduos com a história e a sociedade, partindo de seu próprio contexto, proporcionando a compreensão e o respeito à alteridade do outro, o que é possível quando ela é reconhecida como uma possibilidade passível de ser humana; como uma possibilidade constitutiva de si mesma. 
Há, desse modo, duas concepções de cultura que não se negam ou se excluem, mas se completam e complementam, permitindo ao significado da palavra tomar sentidos diferentes de acordo com cada contexto, sendo compreendido tanto em uma acepção mais particularista quanto em uma acepção mais universalista, possibilitando à Educação Física compreender que ambos os sentidos contribuem para a ampliação do conhecimento sobre a cultura corporal.

Dessa forma, Cuche (2002) arremata:

Tomados como princípios metodológicos, o relativismo cultural e o etnocentrismo não são então contraditórios, mas, ao contrário, complementares. Sua utilização combinada permite ao pesquisador apreender a dialética do igual e do outro, da identidade e da diferença, ou seja, da Cultura e das culturas, que é o fundamento da dinâmica social. (CUCHE, 2002, p. 244)

Culture or cultures? Conceptions of culture in physical education in the perspective of Cuche

\begin{abstract}
Aiming to analyze and correlate some works in the area of Physical Education according to the meanings of culture specified by Cuche (2002), this paper intended to emphasize which perspectives these parameters are based on and what are the conceptions of body culture stipulated by each one. Although the definitions are not so clearly evident very often, it was possible to observe trends of approach to either view, being sometimes understood in a universalist conception and sometimes in a particularist conception. It was possible to consider that these definitions are not opposed, but fit together according to each context, enabling to Physical Education comprehend that both senses contribute to the expansion of knowledge about body culture.
\end{abstract}

Keywords: Physical Education. Body culture. Epistemology.

¿Cultura o culturas? Conceptos de cultura en la educación física en la perspectiva de Cuche

\title{
Resumen
}

Con el objetivo de analizar y correlacionar algunas obras en el área de Educación Física de acuerdo a los significados de la cultura especificado por Cuche (2002), este trabajo pretende hacer hincapié en qué perspectivas de estos parámetros se basan en. Aunque las definiciones no son tan evidentes, es posible observar tendencias de aproximación a cualquiera de las vistas, a veces en una concepción uni- 
versalista y a veces en una concepción particularista. Se puede considerar que estas definiciones no se oponen, pero encajan de acuerdo a cada contexto, lo que permite la Educación Física comprender que los dos sentidos contribuyen a la expansión del conocimiento sobre la cultura del cuerpo.

Palabras clave: Escuela de Educación Física. Cultura del cuerpo. Epistemología.

\section{Referências}

BETTI, M. Educação Física escolar: ensino e pesquisa-ação. Ijuí: Unijuí, 2009.

BRACHT, V. Educação Física/Ciências do esporte: que Ciência é Essa? Revista Brasileira de Ciências do Esporte, Campinas, v. 14, n. 3, p. 111-118. 1993.

BRASIL. Ministério da Educação e do Desporto. Secretaria de Educação Fundamental. Parâmetros Curriculares Nacionais: Educação Física, $3^{\circ}$ e $4^{\circ}$ ciclos. Brasília, MEC/SEF, 1998. v. 7.b.

. Secretaria de Educação Fundamental. Parâmetros Curriculares Nacionais: Pluralidade cultural, orientação sexual/Secretaria de Educação Fundamental. Brasília: MEC/SEF, 1997. v. 10.

CUCHE, D. A noção de cultura nas Ciências Sociais. Bauru: Edusc, 2002.

DAOLIO, J. A cultura da/na Educação Física. 2002. 112 f. Tese (Livre docência) - Faculdade de Educação Física, Universidade Estadual de Campinas, Campinas, 2002.

A educação física escolar como prática cultural: tensões e riscos. In: DAOLIO, J. (Org.). Educação física escolar: olhares a partir da cultura. Campinas: Autores Associados, 2010.

Educação Física e o conceito de cultura. Campinas: Autores Associados, 2007.

. Fenômeno social esporte na formação profissional em Educação Física. Revista da Educação Física. v. 9 n. 1. p. 111-115, Maringá, 1998. 
FORQUIN, J. C. Escola e Cultura: as bases sociais e epistemológicas do conhecimento escolar. Porto Alegre: Artes Médicas, 1993.

GEERTZ, C. A interpretação das culturas. Rio de Janeiro: Guanabara Koogan. 1989.

SOARES, C. L. Educação Física escolar: conhecimento e especificidade. Revista Paulista de Educação Física, p. 6-12, 1996. Suplemento 2 .

.; TAFFAREL, C. N. Z.; VARJAL, E.; CASTELLANI FILHO, L.; ESCOBAR, M. O.; BRACHT, V. Metodologia do ensino da educação física. São Paulo: Cortez, 1992.

Recebido em: 26/06/2011

Revisado em: 14/10/2011

Aprovado em: 18/01/2012

Endereço para correspondência

surayacd@rc.unesp.br

Suraya Cristina Darido

Universidade Estadual Paulista Júlio de Mesquita Filho

Instituto de Biociências de Rio Claro, Departamento de Educação Física

Av. 24 A, No 1515

Bela Vista

13506-000 - Rio Claro, SP - Brasil 